\title{
Change of Communication Strategy to Increase Engagement during the SARS-Cov-2Pandemic: The Experience of the European GEMMA Project in Italy
}

\author{
Cupaioli Francesca Anna ${ }^{1}$, Corrivetti Giulio 2 , Tamburro Ilaria ${ }^{3}$, Fasano Alessio ${ }^{4}$, Mezzelani \\ Alessandra $^{1^{*}}$ \\ ${ }^{1}$ Institute of Biomedical Technologies, National Research Council, Via Fratelli Cervi 93, 20090, Segrate, Italy \\ ${ }^{2}$ ASL Salerno, Via Nizza, 146, 84124 Salerno SA \\ ${ }^{3}$ EBRIS Foundation, Via Salvatore de Renzi, 3, 84125 Salerno SA
}

${ }^{4}$ Mucosal Immunology and Biology Research Center, Center for Celiac Research and Treatment, and Division of Pediatric Gastroenterology and Nutrition, Massachusetts General Hospital - Harvard Medical School, 55 Fruit Street, Boston, MA, 02114, USA.

*Corresponding Author: Mezzelani Alessandra, Institute of Biomedical Technologies, National Research Council, Via Fratelli Cervi 93, 20090, Segrate, Italy

\begin{abstract}
Scientific projects need solid communication plan. GEMMA is a multicenter EU-Horizon2020 project for biomedical research in autism requiring the enrollment of 600 infants at risk of developing autism in different countries. The Communication\& Dissemination work-package had the early goal to create engagement among autism related stakeholders to maximize children recruitment also through social media and website. Because ofCOVID-19 lockdown, the recruitment has been temporarily suspended, as well as schools suspended face-to-face lessons opting for remote teaching. Since children with autism suffer discomfort with routine changes and need special distance education, GEMMA communication has turned toward a COVID-19ad-hoc strategy developing or selecting "technology and inclusion" webinars and "inclusive apps". These sustained children with autism, their parents and teachers in special distance education and entertainment. The results showed the success of specific inclusive tools and languages in scientific outreach activities and the possibility to maintain stakeholder engagement also in emergency situation.
\end{abstract}

Key words: COVID-19, Lockdown, Change of strategy, Public engagement, Science and technology, Social inclusion, Accessibility, Distance education

Abbreviations: Autism Spectrum Disorder, ASD; Communication and Dissemination, C\&D; European Commission, EC; Genome, Environment, Microbiome and Metabolome in Autism, GEMMA; Istituto Superiore di Sanità, ISS; National Research Council, CNR.

\section{INTRODUCTION}

Autism Spectrum Disorder (ASD) is a complex neurodevelopmental disorder characterized by impairment of communication, language and social interaction, restricted range of activities and interests, and repetitive behaviour (https://www.who.int/news-room/fact-sheets/detail/autismspectrum-disorders). Symptoms manifest within the first years of age, are often associated with one or more comorbidities including gastrointestinal and sleep disorders, sensory sensitivities and cognitive impairment [1] and tend to persist life time. ASD affects 1:68 children worldwide causing personal and familial dramatic consequences and representing the higher costs for healthcare system.

Although great effort has been made in biomedical research to better define the pathogenesis of ASD, there are no proven biomarkers or scientific evidences explaining the mechanisms leading to its onset.

In 2018, the European Commission (EC) has selected and financed GEMMA project [2] as part of its Horizon 2020, the biggest EU Research and Innovation program. The grant consists of 14,2M€ in 5years project starting January 2019. GEMMA, which stands for Genome, Environment, Microbiome and Metabolome in Autism, is a multicenter EC Project for exploring interactions between gut 
microbiome, metabolome, epigenome and immune function in order to discover new biomarkers useful for early diagnosis of autism and as potential targets for preventive personalized therapies and, ultimately, disease interception in infants at risk of ASD (siblings of children with ASD, since they have a 10x higher risk to develop this neurodevelopmental disorder).

GEMMA development is based on the enrollment and in-depth evaluation of 600 infants at risk observed from birth and followed over time. Finally, the project will collect and analyse biospecimens from all the children involved generating a unique biobank of about 16,000 blood, stool, urine and saliva samples that can be exploited in future multi-omic studies. To this purpose, the recruitment centers are located in three different countries to take in account for geographical and environmental differences. The countries and centers are:

- Ireland: National University of Ireland Galway (NUIG) (www.nuigalway.ie )coupled with the Irish Centre for Autism and Neurodevelopment Research (ICAN)

- U.S.A.: The Lurie Center, General Hospital Corporation, MGH, Boston, www.partners.org

- Italy: ASL Salerno, Italy (www.aslsalerno.it/),Policlinico di Napoli (http://www.Policliniconapoli .it/), Azienda Ospedaliero-Universitaria S. Giovanni di Dio e Ruggi D'Aragona Scuola Medica Salernitana (http://www.sangiovannieruggi.it/), Ospedale Ruggi (Sa), Ospedale di cava dei Tirreni (SA), Ambulatorio Neuropsichiatria dell'Infanzia e dell'Adolescenza (NPIA) (Ce).

The National Research Council (CNR) of Italy leads the Communication and Dissemination (C\&D) work package and has released the C\&D Plan at month 6 . This plan integrates:

contractual obligations reported in article 29 and 38 of the GEMMA Grant Agreement (N. 825033) for a two-way exchange, such as obligation to inform on EU funding, create a project web site and an open data repository, publish in open access mode and participate to international conferencesetc.;

- what suggested in $\mathrm{H} 2020$ guidelines for $\mathrm{C} \& \mathrm{D}$, including the use of social media (https://ec.europa.eu/research/participants/docs/h2020-funding-guide/grants/grant-

management/communication_en.htm);

- what provided in the proposal and some new implementations, especially referring to communication strategy (see chapter below).

Since the recruitment of 600 infants at risk of autism that meet the inclusion criteria represents one of the main challenges of the project, GEMMA early activity was planned to especially maximize the involvement of parent associations, family groups, medical doctors and other non-profit organizations, other than general public, through a viral communication.

In this way GEMMA should reach as many families and doctors connected to autism as possible and create expectations from and trust in the project. Thus, the parents waiting a baby at risk of ASD should be interested to include the newborn in the enrollment and participate in the study. If successful, communication will allow to recruit the planned number of children.

Due to the topic of the project regarding a neurodevelopmental disorder that involves many children and their families, the communication strategy was based on the "emotional" and "inclusive" aspects that should increase the engagement and involvement of associations and groups of families connected to autism. To this purpose we developed an accessible website (https://www.gemmaproject.eu/) that probably made GEMMA the European project that first communicated following some principles of the Universal Design (UD) and the Web Accessibility Initiative (W3C) (https://www.w3.org/).

Indeed, the website included in the top right position of each pages a free basic accessibility tool: User Way (https://userway.org/).This tool "is helpful accessibility plugins that work without refactoring your website's existing code and will increase compliance with the Web Content Accessibility Guidelines (WCAG) 2.1, Authoring Tool Accessibility Guidelines (ATAG) 2.0, Americans with Disabilities Act (ADA), \& Section 508 requirements». Once clicked, User Way opens a menu offering a panel of tools that allow people with disabilities using the website and making the web accessible benefits individuals, society and businesses. User Way functions are described in table1. 
Change of Communication Strategy to Increase Engagement during the SARS-Cov-2Pandemic: The Experience of the European GEMMA Project in Italy

Table1. Functions of Use Way, a basic accessibility tools (https://userway.org/).

\begin{tabular}{|l|l|}
\hline Accessibility tools & Functions \\
\hline Keyboard Navigation & Allows navigation of the web page using only the keyboard. \\
\hline Screen Reader & Identifies and interprets the text shown on a computer screen \\
\hline Increase Text Size & Makes every part of web site instantly more readable \\
\hline Stop Animations & $\begin{array}{l}\text { Disable animations, blinking and flashing content of web site that } \\
\text { distracts and may trigger seizures }\end{array}$ \\
\hline Tooltips & Display informative text with a simple mouse hover \\
\hline Convert to Accessible Fonts & $\begin{array}{l}\text { Convert stylized fonts into accessible fonts and font weights that are } \\
\text { essential for visually impaired and dyslexic users }\end{array}$ \\
\hline Highlight Links & $\begin{array}{l}\text { Emphasizes links, buttons and action elements in clear, high-contrast } \\
\text { colours that are easy to identify }\end{array}$ \\
\hline Large Cursor & $\begin{array}{l}\text { Increase the standard cursor size by 400\% to ensure the pointer always } \\
\text { remains in sight }\end{array}$ \\
\hline Reading Guide & Converts the cursor into a high contrast horizontal reading guide. \\
\hline Dark Mode & $\begin{array}{l}\text { High contrast dark colour theme that increases the readability of all } \\
\text { elements of the site }\end{array}$ \\
\hline Light Mode & High contrast light colour theme \\
\hline Invert Colours & $\begin{array}{l}\text { Full colour inversion for all site elements providing greater perceived } \\
\text { colour depth }\end{array}$ \\
\hline Text Spacing & $\begin{array}{l}\text { Modifies text and line spacing for improved readability for dyslexic and } \\
\text { visually impaired users }\end{array}$ \\
\hline Colour Desaturation & Desaturates all colours on the page \\
\hline Reveal Page Structure & $\begin{array}{l}\text { Shows page headings, landmarks and links in a clear, structured, easily } \\
\text { navigable and accessible manner }\end{array}$ \\
\hline Reset all configurations & Reset all options back to "off" state \\
\hline
\end{tabular}

Moreover, since the project refers to autism that is often associated with cognitive disorders, hypersensory and anxiety, one of the key focus of our communication is to make GEMMA website as accessible as possible to everybody and especially to patients suffering from ASD. To this purpose we followed some suggestions, reported in table2, to design understandable and comfortable pages for people suffering from anxiety and hyper sensory (https://ukhomeoffice.github.io/accessibilityposters/posters/accessibility-posters.pdf).

Table2. Suggestions to design understandable and comfortable pages from https://ukhomeoffice.github.io laccessibility-posters/posters/accessibility-posters.pdf.

\begin{tabular}{|l|l|l|l|}
\hline \multicolumn{4}{|c|}{ Designing website } \\
\hline autism-friendly & No & Yes & No \\
\hline Yes & $\begin{array}{l}\text { Use bright contrasting } \\
\text { colours }\end{array}$ & $\begin{array}{l}\text { Give users enough time } \\
\text { to complete actions }\end{array}$ & $\begin{array}{l}\text { Rush users or set } \\
\text { impractical time limits }\end{array}$ \\
\hline Use simple colour & $\begin{array}{l}\text { Use figures of speech and } \\
\text { idioms }\end{array}$ & $\begin{array}{l}\text { Explain what will happen } \\
\text { after completing a service }\end{array}$ & $\begin{array}{l}\text { Eave users confuse about } \\
\text { next steps or timeframes }\end{array}$ \\
\hline $\begin{array}{l}\text { Urite in plain language simple sentences } \\
\text { and bullets }\end{array}$ & Create a wall of text & $\begin{array}{l}\text { Make important } \\
\text { information clear }\end{array}$ & $\begin{array}{l}\text { Leave users uncertain } \\
\text { about the consequences } \\
\text { of their actions }\end{array}$ \\
\hline $\begin{array}{l}\text { Make buttons } \\
\text { descriptive }\end{array}$ & $\begin{array}{l}\text { Make buttons vague and } \\
\text { unpredictable }\end{array}$ & $\begin{array}{l}\text { Give users the support } \\
\text { they need to complete a } \\
\text { service }\end{array}$ & $\begin{array}{l}\text { Make support or help } \\
\text { hard to access }\end{array}$ \\
\hline $\begin{array}{l}\text { Build simple and } \\
\text { consistent layouts }\end{array}$ & $\begin{array}{l}\text { Build complex and } \\
\text { cluttered layouts }\end{array}$ & $\begin{array}{l}\text { Let user check their } \\
\text { answers before they } \\
\text { submit them }\end{array}$ & $\begin{array}{l}\text { Leave users questioning } \\
\text { what answers they gave }\end{array}$ \\
\hline
\end{tabular}

A GEMMA Facebook account was created by Ebris Foundation (GEMMA Ebris Autismo https://www.facebook.com/ilaria.ebris.5) and two pages were created for Italian (Progetto Gemma Italia: https://www.facebook.com/Progetto-GEMMA-Italia-110247750431245/?modal=admin_todo_ tour) and English (GEMMA - project Autism - USA:https://www.facebook.com/GEMMA-projectAutism-USA-100183788222436/?modal=admin_todo_tour) version. By the Facebook Italian page, we contact Italian family groups involved in ASD such as ASD associations, organizations working about disabilities and rehabilitation, register of doctors, psychologists as well as some radio programs. 
During 2019, the page has released posts about project content and objectives highlighting the need to enroll children at risk of developing autism. We also shared the interview that the GEMMA coordinator Prof. Alessio Fasano gave at "Conversations that matters" on the occasion of the award "Dr. Rogers prize" 2019 (https://www.youtube.com/watch?v=OJKH7qaoWAI\&feature=emb_share \&fbclid=IwAR0nUR7kGpzDChEIP6UYdD0B_xjxJHN_C5KjqY-Xjy4sT_I4FC1geBtLlU8 ).

During the first year of project, we also published three press releases in the CNR News webpage summarizing the posts released in the Italian Facebook page (https://www.cnr.it/it/cerca?Search =gemma ).

To maximize the engagement in Italy, during the 1st Year Annual General Meeting of GEMMA project that was held at Fondazione Ebris, Salerno, Italy, GEMMA met national and local non-profit organizations whose mission is to share an experience of social solidarity between families, institutions and operators in the social-health sector. In this occasion GEMMA Project has been presented as well as the role of EBRIS Foundation and ASL Salerno in GEMMA and the recruitment for pre-clinical studies.

Two scientific articles were already published in peer reviewed journals in open access modality $[3,4]$ and a third article has just been submitted [2].

Because of SARS-CoV-2 worldwide diffusion and consequent lockdown, the recruitment of children has been suspended in all the three countries, in which the governments shut all childcare facilities, schools and colleges and lessons have been delivered remotely. In Italy, the lockdown started from March $8^{\text {th }}, 2020$ and ended May $18^{\text {th }}$, however social distancing is imposed beyond this date and remote lessons continued up to the end of the school year. Distance teaching has encountered several problems at least during the first weeks. Indeed, many schools and teachers were unprepared for virtual teaching, some areas of Italy were not well served by internet and schools had to provide electronic devices to very needy families who did not have it and to let children attending the lessons.

Moreover, many students with ASD need a support teacher and specific tools and can mostly experience the stress due to the application of containment measures and any home isolation or hospitalization in case of contagion.

For all these reasons, in Italy we changed the GEMMA planned communication activity offering a kind of "service" to spread awareness and solidarity actions and maximize the engagements of stakeholders. To this purpose we recommended general protective procedures against SARS-CoV-2 diffusion and communicate different inclusive didactic courses or supports to assist children with ASD, their families and educators and help them in their school and learning path in this critical period.

To this goal we searched, collected and posted information and link to courses about equity and inclusion in virtual learning as well as a review of the most interesting apps for children with ASD to help schools in serving all of their students and students to attend the lessons.

We also expanded our stakeholders by contacting the Facebook page of associations of mums, teachers, principals, minister of education, association about different disabilities, app designers, women's magazines and football fan pages.

From 2019 up to March 7, 2020, 12 Facebook posts have been released in the Italian Facebook page of the project reaching a maximum of 631 people and 78 interactions while, during pandemic, 11 announcements have been posted reaching 4,243 people and 241 interactions.

Here, we list the content of the Facebook posts published during epidemic. Each one is accompanied by an image that in few cases depends on the cited website, while in most cases is downloaded from "pixabay", an international and free-to-use website for sharing images and illustrations (https://pixabay.com/it/).

In the first post, titled "COVID-19 emergency: \#inclusiveschoolathome" GEMMA project reported the "Essediquadro training" platform created by the CNR Educational Technologies Institute and which provides qualified, certified and free training on "technology and inclusion" themes (https://sd2.itd.cnr.it/corsiformazione ). Inside the platform there is \#scuolainclusivaacasa, a space dedicated to the COVID-19 emergency where teachers can find free operating instructions, talk to 
each other and with experts, report self-produced materials, share ideas, indications and experiences https://sd2.itd.cnr.it/corsiformazione/course/view.php?id=40.

The second one titled "Inclusive apps for children on the autism spectrum" reported "About Inclusive applications for children in the autism spectrum", an in-depth analysis made by the Educational Technologies Institute of CNR within the Essediquadro service (https://sd2.itd.cnr.it), downloadable here:

https://sd2.itd.cnr.it/?r=site\%2Fapprofondimento\&id=218\&tipoapprofondimento=2\&fbclid=IwAR1T Uz43EmvAvYhr5ignHaI-8Uo05h5jmTcPgbYb00Nus_dnJ0B5HTSmxuw .

The document proposes a series of attractive and practical apps that allow children to have multiple resources available on a single support that can be used in various contexts (family, school, rehabilitation, etc).The apps have been selected on the basis of their theoretical foundation, supported by scientific studies or implemented starting from clinical practice and divided according to the objectives of the Italian Individualized Educational Plan (https://www.miur.gov.it/alunni-condisabilita ).

Then again, we posted "COVID-19 and autism: indications from the National Institute of Health [Istituto Superiore di Sanità, (ISS)] to prevent discomfort related to the epidemic". This ISS report has considered all the factors of vulnerability of people with ASD: the communication impairment, the frequent coexistence of intellectual disability, the extreme discomfort with routine changes and environmental contexts and the high risk of developing a psychiatric disorder. Therefore, the distress related to the COVID-19 pandemic and the measures that have been decided to contain it can favour the increase in stereotyped conduct, opposition and aggressive conduct towards oneself, objects and other people and the development of psychiatric co morbidities. Furthermore, some people on the autism spectrum may not be able to guarantee the management of personal and social risks during the COVID-19 pandemic.

The document offers indications for preventing discomfort and for appropriate support, in different contexts, for people on the autistic spectrum and their families. Among the indications to follow at home it is important that people on the autistic spectrum are supported in maintaining the daily routine: keeping the sleep-wake rhythm, participating in housework, organizing the day through a calendar, being helped to express their feelings through writing activities, movies or games. It is important to maintain, when possible, the interventions of the professionals who have them in charge even remotely, through video calls or telephone calls. In the event of home isolation, collaboration is necessary with a family caregiver equipped with adequate Personal Protective Equipment, who manages health conditions, normal daily activities and helps to prevent the emergence of behavioural emergencies.

Instructions and suggestions for people with ASD that reside in residential facilities or hospitalized were also provided. The document has been developed by the ISS National Autism Observatory with a multidisciplinary group of experts, in collaboration with the Italian Scientific Society of Child and Adolescent Neuropsychiatry (SINPIA), the Italian Society of Psychiatry (SIP), the Italian Society of Psychiatric Epidemiology (SIEP ) and the Italian Society for Neurodevelopmental Disorders (SIDiN) (https://www.iss.it/.../asset_.../1SRKHcCJJQ7E/content/id/5323833 ).

The initiative "Beyond distances", ideas and actions for a more inclusive school was also promoted. The initiative consisted of a series of open webinars about remote accessible didactic organized by Agnelli foundation, Google for education and Gedi Visual with "La Repubblica" on line magazine (https://lab.gedidigital.it/gedi-vis.../2020/oltre-le-distanze/).

Then again, GEMMA posted the website page of the "Center of Autism and Development Disorders" of Ravenna city included in the website of the Local Health Company (Ausl) of Romagna region. The page makes available a very rich suite of funny and functional games, informatics tools, labs, activities and workshops for children in the spectrumhttps://www.auslromagna.it/organizzazione/retiprogrammi/autismo/ravenna?fbclid=IwAR3z9Ko9SKHsZH0Qz12gqaBVkPRIsO1pCeB785swPTzH8 HD0plwh1oh7vlY.

An interesting post, refers to a story that explain to children with cognitive delay what is happening. The story is explained by Francesca Dall'Ara and illustrated by Giada Negri (IRCCS Ca 'Granda 
Hospital Maggiore Policlinico Foundation in Milan) https://www.policlinico.mi.it/uploads/fom/ attachments/pagine/pagine_m/78/files/allegati/545/storia_di_un_coronavirus_-_secondo_finale.pdf. Interestingly, the text is fully expressed in symbols by Antonio Bianchi and Laura Bernasconi (Suprazonale Center for Augmentative Communication in Milan and Verdello) following the augmentative communication instructions defined by the study center "Centro studi inbook, csinbook.eu 2020; symbols are from Widgit Literacy symbols (WLS) Widgit Symbols (C) Widgit software 2002-2020 www.widgit.com - www.auxilia.it.

Two surveys were also included in the Facebook Italian page: the first one is an anonymous online questionnaire lasting up to 20 minutes. It is part of a research project curated by the Language and Communication across Modalities Laboratory (LaCAM) of the CNR Institute of Sciences and Technologies of Cognition (ISTC-CNR) on the understanding of some signs LIS (Italian Sign Language). Hearing people who do not know this language is invited to see and understand some words expressed through new signs. These signs were authored by Morgana Proietti, Chiara Bonsignori and Olga Capirci (ISTC-CNR) and signs were done by Alessio di Renzo e Tommaso Lucioli (https://sites.google.com/view/progetto-di-ricerca-lis/home?fbclid=IwAR2gNcvtO94twd5o bZ427EGYWwz3HawQB7ItO8G1SzL3ZRPLKNvirtXiWIk). The second survey was "The family and the school at the time of COVID-19" which aims to understand the management of distance learning and what difficulties it entailed, from the point of view of the families of pupils in school age, from kindergarten to high school (https://survey.itd.cnr.it/index.php/248599). The survey was developed by the Institute for Educational Technologies of the National Research Council (ITD-CNR) in the "COVID-19 Emergency" \#scuolainclusivaacasa (https://www.itd.cnr.it/covid19/).

GEMMA Italian Facebook page also provided "Snail nursery rhyme" to tell children with developmental disorders what is going on (https://drive.google.com/file/d/1sIj7nPTMQ7cTj1Kcw6_ axl-o6EwH5-cC/view?fbclid=IwAR3zH7RcifcOms3mMfF32YDYP7zgcBqh7aHgkAYTCnOaMf-

T3N6jTccWYmo). To make the story simpler and more understandable it was told in symbols through the augmentative communication according to the model defined by the inbook study center csinbook.eu 2020, Widgit Literacy symbols (WLS), Widgit Symbols (C) Widgit software 2002-2020 www.widgit.com - www.auxilia.it. The nursey rhyme was developed by the Woman-Child-Newborn Department of the Child and Adolescent Neuropsychiatry - U.O.N.P.I.A, Polyclinic Foundation of Milan while the version in symbols by the Centro Sovrazonale di Comunicazione Aumentativa of Milan e Verdello (http://sovrazonalecaa.org/).

\section{Materials AND MethodS}

To understand the success and efficacy of our C\&D strategy and activity during COVID-19 pandemic, we analysed the insight of the Italian Facebook page of GEMMA at two different data (June $8^{\text {th }}$ and July $13^{\text {th }}, 2020$ ) and compared the number of people we reached by posts released before and after the lockdown. The posts are classified in pre- and during-lockdown and those duringlockdown in "general information about anti-viral protection" and "service for remote inclusive didactic, entertainments and comfort".

We also analysed the data about the number of people who engaged with the Italian Facebook page of GEMMA (single users) daily and in 28 days (figure 1).

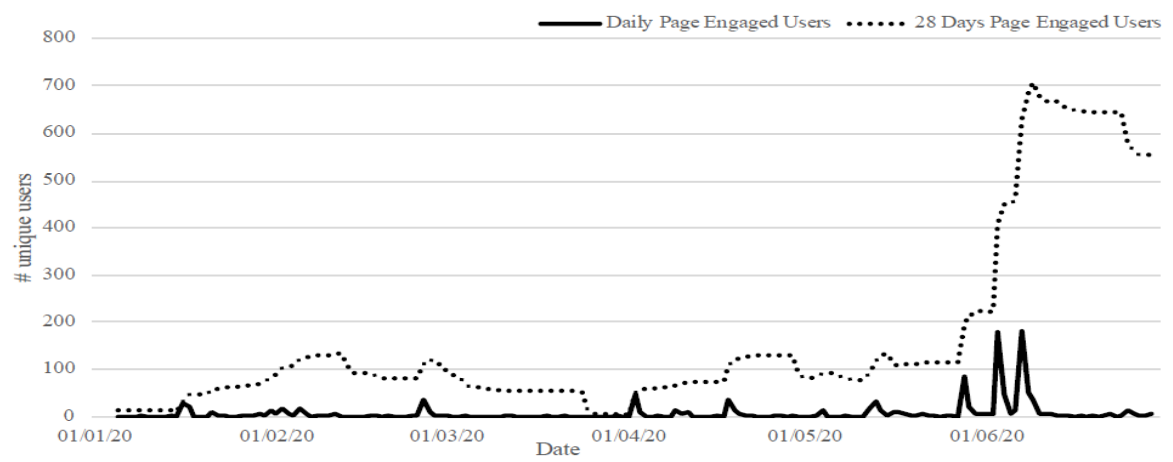

Figure1. The number of people who engaged with the Italian Facebook page of GEMMA. The daily (continuous line) and 28 days (dotted line) page engaged users from January to June 2020: public engagement increased thanks to the COVID-19 ad hoc strategy and involved also the posts released before pandemic. 
All posts of the Italian Facebook page did not benefit from the paid dissemination service of Facebook.

\section{ReSUlts}

During the COVID-19 pandemic lockdown the communication strategies of GEMMA project through Facebook turned introducing posts of public interests aimed to sustain children with autism and/or cognitive disabilities and their relatives and educators. The "inclusive posts" released during the period of remote lessons (from March to June 2020) reached a higher number of people and interactions than posts pre-lockdown (table 3). The higher number of people was involved in the survey "Family and school during COVID-19 pandemic". This reached 4365 single users and of this 244 interacted.

Table3. People reached and engaged by Facebook posts (updated on13 ${ }^{\text {th }}$ July 2020).

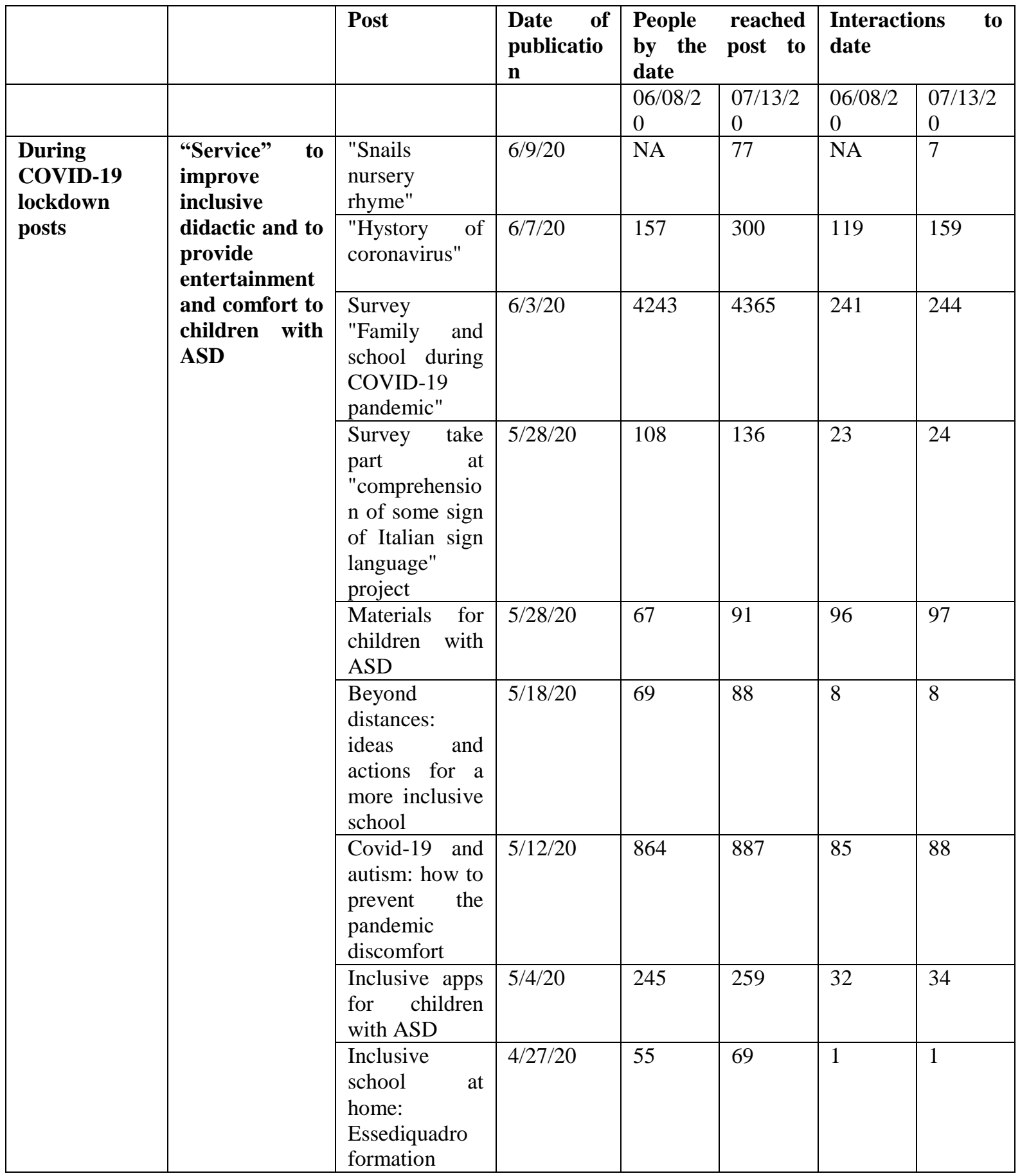


Change of Communication Strategy to Increase Engagement during the SARS-Cov-2Pandemic: The Experience of the European GEMMA Project in Italy

\begin{tabular}{|c|c|c|c|c|c|c|c|}
\hline & \multirow[t]{3}{*}{$\begin{array}{l}\text { "Service" as } \\
\text { general } \\
\text { information } \\
\text { about anti- } \\
\text { viral } \\
\text { protection }\end{array}$} & $\begin{array}{l}\text { Video: } \\
\text { solidarity and } \\
\text { inclusiveness } \\
\text { during } \\
\text { COVID-19 } \\
\text { pandemic }\end{array}$ & $4 / 9 / 20$ & 104 & 132 & 8 & 8 \\
\hline & & $\begin{array}{l}\text { Supporting } \\
\text { Italian Civil } \\
\text { Protection } \\
\text { Department by } \\
\text { Easter eggs } \\
\text { distribution to } \\
\text { patients with } \\
\text { ASD } \\
\end{array}$ & $4 / 9 / 20$ & 69 & 76 & 11 & 11 \\
\hline & & $\begin{array}{l}\text { Shared video } \\
\text { "Coronavirus } \\
\text { and people } \\
\text { suffering from } \\
\text { autism. Two } \\
\text { times victims. } \\
\text { Near their } \\
\text { family" }\end{array}$ & $4 / 3 / 20$ & 46 & 54 & 2 & 2 \\
\hline \multirow[t]{6}{*}{$\begin{array}{l}\text { Pre-COVID- } \\
19 \text { lockdown } \\
\text { posts } \\
\text { following the } \\
\text { GEMMA } \\
\text { communicatio } \\
\text { n plan }\end{array}$} & \multirow[t]{6}{*}{$\begin{array}{l}\text { Communicatio } \\
\text { n of the } \\
\text { project and } \\
\text { recruitment }\end{array}$} & $\begin{array}{l}\text { GEMMA } \\
\text { meets local } \\
\text { and national } \\
\text { no-profit } \\
\text { organization } \\
\text { that support } \\
\text { patients with } \\
\text { autism }\end{array}$ & $2 / 5 / 20$ & 69 & 74 & 1 & 1 \\
\hline & & $\begin{array}{l}\text { First annual } \\
\text { meeting on } \\
\text { GEMMA } \\
\text { project }\end{array}$ & $2 / 2 / 20$ & 631 & 658 & 35 & 35 \\
\hline & & $\begin{array}{l}\text { Interview with } \\
\text { Alessio } \\
\text { Fasano, } \\
\text { GEMMA } \\
\text { project } \\
\text { coordinator }\end{array}$ & $1 / 22 / 20$ & 73 & 78 & 23 & 23 \\
\hline & & $\begin{array}{l}\text { New } \\
\text { recruitment } \\
\text { centres for } \\
\text { GEMMA } \\
\text { project }\end{array}$ & $1 / 17 / 20$ & 386 & 390 & 78 & 78 \\
\hline & & $\begin{array}{l}\text { GEMMA } \\
\text { continues the } \\
\text { recruitment of } \\
\text { children at risk } \\
\text { for ASD }\end{array}$ & $12 / 18 / 19$ & 127 & NA & 18 & NA \\
\hline & & $\begin{array}{l}\text { GEMMA } \\
\text { project } \\
\text { presentation }\end{array}$ & $11 / 14 / 19$ & 92 & NA & 5 & NA \\
\hline
\end{tabular}

The number of people involved on the Italian Facebook page of GEMMA remains constant from January 2020 to May 2020 and strongly increased in June 2020 (figure1). In June, the videos "Hystory of coronavirus" and "Snails nursery rhyme" were shared on the GEMMA Italian Facebook page. These videos are designed with inclusivity criteria for large audience including subjects with cognitive disability. The analytical data about posts at June $8^{\text {th }}$ and July $13^{\text {th }}$ shows that the publication of posts directed to large audience increased the visibility also of the previously unread posts (table 3 ). 


\section{DisCUSSION AND CONCLUSION}

From January, 2019, up to March $7^{\text {th }}$, 2020 GEMMA dissemination activity followed what was planned in the proposal and in the C\&D plan released on June 30, 2019. The plan based the communication strategy on the concept of inclusion. To this purpose we first included a tool for accessibility in the GEMMA website that was also designed following some principles of the Universal Design (UD) and the Web Accessibility Initiative (W3C) (https://www.w3.org).

Our first challenge was to communicate the project to enroll the number of children at risk of developing autism we had planned in the proposal $(\mathrm{N}=600)$. So, we include a pop up in the website that immediately inform about the enrollment. This information was also spread through the Facebook Italian page contacting almost all the Italian associations connected to autism to promote GEMMA and the recruitment.

From March 8th, 2020, SARS-CoV-2 worldwide diffusion and consequent lockdown have suspended most of activities including the face-to face school didactic and, obviously, the recruitment of children to enroll in the project. School lessons have been delivered remotely but some technical and organizational problems emerged in Italy, particularly for student that need special distance education such as children with autism. Indeed, many children in the spectrum, not only need special teaching support but can suffer extreme discomfort from social isolation and routine changes.

In order to increase, or at least maintain, the stakeholder engagement our inclusive strategy has veered from recruitment towards a sort of "service" activity. Indeed, at the beginning we promoted general information about anti-viral protections and then, we searched in qualified websites such as those of government and institutional health, any kind of suggestion, tool and workshop about inclusive distance learning, children entertainment and welfare. So, we released posts about accessible remote teaching, special apps, games, labs and workshop to help and entertain children, families, educators and therapists connected to autism.

Thanks to the communication developed during COVID-19 pandemic, we have attracted more followers and also involved them in answering the surveys we had published. Our Facebook friends and interactions have increased as well as our posts reached more people than before.

Although, because of pandemic most people were at home and probably spent more time on social media, we conclude that our communication as a "service" for families stressed by the pandemic and school problems has been successful and has increased the engagement and involvement in the project.

Acknowledgements: Matteo Gnocchi for the informatic development of GEMMA web site.

Declaration of Conflicting Interests: The Authors declare that there is no conflict of interest.

Funding Acknowledgement: GEMMA EU project, grant agreement No 825033;

Author contributions: A.M contribution "A.M.: responsible of GEMMA C\&D WP, conceived and designed the C\&D plan, the web site the Facebook communication and wrote the manuscript." F.A.C.: involved in C\&D, figures and tables preparation, revision of the manuscript. G.C. and I.T.: Facebook communication, AF: GEMMA coordinator, final revision of the manuscript.

\section{REFERENCES}

[1] Mezzelani, A., Landini, M., Facchiano, F., Raggi, M. E., Villa, L., Molteni, M., De Santis, B., Brera, C., Caroli, A. M., Milanesi, L., Marabotti, A. Environment, dysbiosis, immunity and sex-specific susceptibility: a translational hypothesis for regressive autism pathogenesis. Nutritional neuroscience (2015) 18(4), 145-161. https://doi.org/10.1179/ 1476830513Y.0000000108.

[2] Troisi, J., Autio, R., Beopoulos, T., Bravaccio, C., Carraturo, F., Corrivetti, G., Cunningham, S., Devane, S., Fallin, D., Fetissov, S., Gea, M., Giorgi, A., Iris, F., Joshi, L., Kadzielski, S., Kraneveld, A., Kumar, H., Ladd-Acosta, C., Leader, G., Mannion, A., Maximin, E., Mezzelani, A., Milanesi, L., Naudon, L., Peralta Marzal, L., Perez Pardo, P., Prince, N., Rabot, S., Roeselers, G., Roos, C., Roussin, L., Scala, G., Tuccinardi, F., Walker, A., Fasano, A. Genome, Environment, Microbiome and Metabolome in Autism (GEMMA) study design: biomarkers identification for precision treatment and primary prevention of autism spectrum disorders by an integrated multi-omics systems biology approach" submitted to Contemporary Clinical Trials. 
Change of Communication Strategy to Increase Engagement during the SARS-Cov-2Pandemic: The Experience of the European GEMMA Project in Italy

[3] Di Nanni, N., Bersanelli, M., Cupaioli, F. A., Milanesi, L., Mezzelani, A., \& Mosca, E. Network-Based Integrative Analysis of Genomics, Epigenomics and Transcriptomics in Autism Spectrum Disorders. International journal of molecular sciences (2019) 20(13), 3363. https://doi.org/10.3390/ijms20133363.

[4] Cupaioli, F. A., Mosca, E., Magri, C., Gennarelli, M., Moscatelli, M., Raggi, M. E., Landini, M., Galluccio, N., Villa, L., Bonfanti, A., Renieri, A., Fallerini, C., Minelli, A., Marabotti, A., Milanesi, L., Fasano, A., \& Mezzelani, A. Assessment of haptoglobin alleles in autism spectrum disorders. Scientific reports (2020) 10(1), 7758. https://doi.org/10.1038/s41598-020-64679-w.

Citation: Cupaioli Francesca Anna, et.al. "Change of Communication Strategy to Increase Engagement during the SARS-Cov-2Pandemic: The Experience of the European GEMMA Project in Italy" International Journal of Humanities Social Sciences and Education (IJHSSE), vol 7, no. 9, 2020, pp. 128-137. doi: https://doi.org/10.20431/2349-0381.0709013.

Copyright: (c) 2020 Authors. This is an open-access article distributed under the terms of the Creative Commons Attribution License, which permits unrestricted use, distribution, and reproduction in any medium, provided the original author and source are credited. 